\title{
El Poema de Gilgamesh: algunas preguntas desde la etnobotánica, la psicofarmacología y la confrontación con los mitos clásicos
}

\author{
The Epic of Gilgamesh: some questions from the etnobotany, \\ psychopharmacology and the confrontation with \\ the classical myths
}

Carlos G. Wagner*

RESUMEN

Algunos pasajes del Poema de Gilgamesh interpretados desde una perspectiva etnobotánica y psicofarmacológica, sugieren, con la ayuda de los mitos clásicos, la presencia de prácticas rituales relacionadas con plantas visionarias.

PALABRAS CLAVE:

Gilgamesh, Humbaba, trances, visiones, enteógenos.

\section{ABSTRACT}

Some passages in the Epic of Gilgamesh interpreted from ethnobotanical and psychopharmacological perspective, suggest, with the help of classical myths, the presence of ritual practices relating to visionary plants.

\section{KEYWORDS:}

Gilgamesh, Humbaba, trance states, visionary experiences, entheogens.

La literatura académica generada por el Poema de Gilgamesh es del tal magnitud que cualquier intento de reproducirla en este breve ensayo no sería otra cosa que ridículo. Por otro lado, nuestra aproximación, que pensamos novedosa, se interesa por algunas de las experiencias y visiones que en él se relatan desde una perspectiva interdisciplinar, en que la Etnobotánica y la Psicofarmacología, con lo que aportan de conocimiento sobre los llamados «enteógenos»" ${ }^{1}$, pueden resultar

* Universidad Complutense de Madrid. E-mail: cgwagner@his.ucm.es

1 Neologismo cuyo significado es el de «dios generado dentro». Un término acuñado para definir con mayor exactitud la acción provocada por ciertas drogas en aquellos que las ingerían en el curso de algunas ceremonias que constituían el núcleo de varios cultos mistéricos en la Antigüedad. La expe- 
clarificadoras, no habiendo sido utilizadas hasta el momento, según nuestro conocimiento, en este contexto.

\section{EL GUARDIÁN DEL BOSQUE DE LOS CEDROS}

Algunos de los personajes de los mitos griegos nos recuerdan una figura bien conocida de la tradición sumerio/acadia: el gigante Humbaba, guardián del Bosque de los Cedros en cuya montaña habitaban los dioses. En el Poema de Gilgamesh se dice que su boca era de fuego, su aliento la misma muerte, su grito como un diluvio, que oía en seiscientos kilómetros a la redonda cualquier sonido del bosque y tenía un rostro terrible y monstruoso ${ }^{2}$. Se trata de la encarnación de una fuerza primordial de la naturaleza, imponente y agresiva, cuya misión es proteger los árboles sagrados por mandato del propio Enlil. Se decía que no había tenido padre ni madre y que había nacido en la montaña engendrado en un tiempo inmemorial por Utu, el Sol. En otra versión del poema, el propio Humbaba dice haber nacido en una cueva en la montaña, lo que (cueva, montaña, árbol/bosque de cedros) evoca las tradiciones chamánicas sobre el axis mundi. Como se decía que el adyton desde el que la Pitia vaticinaba en Delfos, era un «onfalos», el ombligo o centro del mundo, representado por una piedra cónica, donde se habían cruzado las dos águilas enviadas por Zeus desde dos puntos opuestos del universo. Un axis mundi que comunicaba el mundo de los hombres con el de las divinidades y la morada de los muertos. Mesopotámicos y griegos parecen haber compartido unas mismas creencias sobre cosmogonia primitiva, tal vez derivadas de un pasado remoto de rituales y prácticas chamánicas ${ }^{3}$.

Se le representaba a Humbaba con cara de león, dientes de dragón, gruesa melena y enormes pies y estaba formado por innumerables surcos, circunvalaciones al estilo del los pliegues del cerebro o los intestinos. A su boca de fuego, su voz de trueno y su aliento destructivo se añade la capacidad de petrificar con su sola visión igual que la Gorgona Medusa. Su cara se transforma en una espantosa máscara cuando observa a Gilgamesh abatiendo los cedros. Máscara, distorsionada y horrible, que era muy conocida ya que se reproducía en amuletos y en la que algunos han visto un antecedente e incluso un modelo de la cabeza clásica de Medusa $^{34}$, un ser igualmente petrificante.

riencia que provocaban difiere radicalmente del sueño narcótico causado por el opio o de la exaltación jubilosa que suele inducir el cannabis, también utilizados ritualmente con fines religiosos en el mundo antiguo. Por el contrario, bajo el efecto de un enteógeno, el sujeto se mantiene despierto mientras perdura su influencia, inmerso en una experiencia que le será difícil explicar con palabras habituales. Un trance místico (un psiquiatra preferiría denominarlo "excursión psíquica») que le produce un tremendo impacto anímico y espiritual y que le aporta un tipo de certidumbre que por ninguna otra vía de conocimiento, salvo el duro camino emprendido por los ascetas, es posible alcanzar. 104 ss.

2 BOTTERO, J, La epopeya de Gilgamesh. El gran hombre que no quería morir, Madrid, 1998, p. 47 ss.

WAGNER, C. G, «Psicoactivos, misticismo y religión en el mundo antiguo», Gerión, 2 (1984), pp.

${ }^{4}$ CASSIN, E., La Splendeur divine, Introduction a l'etude de la mentalite mesopotamienne, Paris, 1968 , p. 55, n. 8. 
El Poema de Gilgamesh: algunas preguntas desde la etnobotánica...

Según el profesor Lara Peinado5: «Con Humbaba nos hallamos ante la figura simbólica y universal del dragón, animal fabuloso que se encuentra en la mayoría de los mitos y leyendas del mundo. Tal ser, Humbaba, es en el Poema la tipificación animal por excelencia, la más pura idea del adversario, en el mismo concepto que luego atribuiría la civilización cristiana al diablo. En el Poema, Humbaba aparece casi deificado, encargado por los dioses de guardar la morada sagrada de los mismos, idea que cuadra con una de las funciones simbólicas de los dragones: la vigilancia. Gilgamesh y Enkidu, al igual que tiempo después Apolo, Cadmo, Perseo y Sigfrido, sin olvidar a San Jorge y a San Miguel, vencen al dragón, logran domeñar a una fuerza del mal...

En un momento determinado Gilgamesh concibe una serie de proyectos destinados a ganar inmensa gloria y hacer inmortal su nombre y el de su amigo. Logra convencer a Enkidu y así ambos héroes se aprestan a efectuar un largo y peligroso viaje, que contendrá -como todos los viajes heroicos- el sentido de la derrota del Mal, encarnado en el monstruo Humbaba, terrible dragón, según se dijo, al que sólo se le podría hacer frente gracias a poderes mágicos o a la protección de los dioses.

Todos estos requisitos se dan en el episodio del Bosque de los Cedros, verdadera pieza maestra de «violencia sagrada». Dicha aventura equivalía explícitamente al intento de apoderarse de la inmortalidad. El Bosque era el País de la Vida, la tierra de los dioses inmortales, su escondida morada, plena de símbolos riquísimos para la mentalidad primitiva.»

\section{LA MONTAÑA DE LOS DIOSES Y LA IDENTIDAD OCULTA DE HUMBABA}

En muchos mitos y leyendas de diferentes culturas, la montaña sagrada alberga en su cumbre un espacio propicio para la estancia de los dioses, mientras que a sus pies se abre el oscuro mundo subterráneo poblado por seres monstruosos. Ya que el monstruoso Humbaba había sido engendrado en la Montaña, morada de los dioses, por el Sol, cabría preguntarse que clase de criatura era. Al parecer, su esencia era divina motivo por el cual ni los propios dioses podían hacerle frente. Pero un nacimiento en un montaña como consecuencia de la acción del sol recuerda de cerca la génesis de algún tipo de planta o tal vez un hongo (aunque se pensaba que estos nacían de los rayos de la tormenta). Sobre todo si consideramos que haber sido engendrado en una cueva le acerca mucho a los seres del inframundo y que los hongos son, seguramente, ya que crecen bajo tierra, los más característicos de estos seres.

¿Poseía originariamente Humbaba una identidad botánica semejante? De hecho habitaba en un bosque de árboles sagrados a los que protegía, pero el mismo no era uno de ellos. ¿Por qué eran sagrados los árboles? En el Libro de los Sal-

5 LARA PEINADO, F, «Poema de Gilgamesh: un viaje fallido a la inmortalidad», Antiqua. Jornadas sobre la Antigüedad (2009) pp. 9 y 11. 
$\operatorname{mos}^{6}$ aún se los denomina «divinos cedros» o «cedros de un dios». En el texto sumerio se utiliza el vocablo ERIN y así los árboles ERIN parecen designar distintas especies de cedro ${ }^{7}$. La palabra «cedro» proviene del latín cedrus que a su vez procede del griego kedros, con la que se denominaba también al enebro. Resulta interesante saber que el aceite destilado de algunos tipos de cedros y de los enebros contiene una esencia muy similar al thujol o tanacetol con propiedades estimulantes y psicoactivas ${ }^{8}$. Por otra parte, el denominado «cedro blanco» (juniperus oxycedrus), que es mencionado en la mayor parte de las farmacopeas mesopotámicas $^{9}$, contiene en su esencia o aceite los mismos principios básicos. Este tipo de árboles ha sido utilizado por la sibila Dainyal de las tribus del Hindo Kush que inhalaba el humo desprendido al quemar algunas de su ramas, así como por los chamanes turcos, los mongoles Buriat o los druidas celtas ${ }^{10}$. Así que no sería extraño considerar que su protector fuera otra especia botánica de similares o más potentes características.

El aceite esencial de los cedros del Líbano era uno de los ingredientes fundamentales en las técnicas de momificación egipcias. $Y$ en dosis elevadas resulta neurotóxico ${ }^{11}$. "The Cedar of Lebanon is cited numerous times in religion and mythology. In addition to its significant role in the Epic of Gilgamesh, the Cedar of Lebanon is regarded as a world tree in several mythological passages»12. Según la mitología sumeria, Inanna, que en los himnos procedentes de Nipur es llamada «Señora del EDIN», adquiere el conocimiento después de comer de uno de esos cedros. Así que los cedros que guardaba Humbaba son también el Arbol del Conocimiento.

En la versión sumeria del poema, Gilgamesh goza de la ayuda que le proporciona Utu en forma de «los Siete que brillan en el Cielo», lo que indica su naturaleza estelar, encargados de guiarle en su viaje. Se trata, en definitiva de las Pléyades que han de orientarle hasta alcanzar el Bosque de los Cedros, cuya localización resulta insegura ${ }^{13}$, aunque suele asumirse de forma generalizada que se encontraba en las montañas del Líbano. No obstante se han propuesto otras localizaciones diferentes, como Elam, Norte de Siria (Amanus), Dilmún o los Zagros $^{14}$.

\footnotetext{
$680,10$.

7 HANSMAN, J., «Gilgamesh, Humbaba and the Land of The Erin-Trees», Iraq, 38 (1976) pp. 24 y 27 ss.

8 ALBERT-PULEO, M., «Mythobotany, pharmacology and Chemistry of thujone-containing plants and derivates», economic Botany, 32 (1978), pp. 65-74

9 CONTENAU, G., « Drogues de Canaan, d’Amurru et jardins botaniques», Mélanges Syriens offerts a René Dussaud, vol. 1, Paris, 1939, p. 12.

10 GODBEY, A. E., «Incense and Poison ordeals in the Ancient Orient», The American Journal of Semitic Languages and Literatures, 46, 4 (1930) pp. 234 ss.

11 Vid. n. 50.

12 MASRI, R, «The Cedar of Lebanon: Culture, History, and Ecology», The Cedars of Lebanon: Significance, Awareness and Management of the Cedrus Libani in Lebanon: http://almashriq.hiof.no/lebanon/300/360/363/363.7/transcript.html\#s3

${ }_{13}$ BILIC, T., «A Note on the Celestial Orientation: Was Gilgamesh guided to the Cedar Forest by the Pleyades?»; VAMZ, 3. s, XL (2007) pp. 11-14.

14 HANSMAN, J., «Gilgamesh..., pp. 26 ss.
} 
El Poema de Gilgamesh: algunas preguntas desde la etnobotánica...

Después de atravesar siete montañas Gilgamesh y su compañero Enkidu llegan por fin al Bosque de los Cedros (que unos sitúan en el Norte y otros en el Este, mientras que en la versión A del poema se menciona Arata, que apunta hacia el Este pero con un fuerte contenido mítico similar al de Dilmún, lugar en que se localiza el paraíso sumerio), donde derrotan a Humbaba, cortándole la cabeza, que guardan en un bolsa de cuero ${ }^{15}$. No obstante, si era un gigante ¿no sería su cabeza también gigantesca así como el recipiente destinado a contenerla? Nada de esto se deduce del texto, por lo que cabe abrigar la sospecha de que su tamaño gigantesco no sea más que una metáfora, así como sus terribles poderes, de su verdadero poder y naturaleza. También en un fragmento ugarítico del poema, Gilgamesh y Enkidu quedan paralizados e inconscientes por el efecto que les provoca el aura de Humbaba ${ }^{16}$, lo que recuerda un tanto la capacidad de petrificar de la famosa Medusa a aquellos que la miraran directamente. Pero los paralelismos continúan: Al igual que Medusa «perdió la cabeza» a manos de Perseo, también habrá de perderla Humbaba. «Perder la cabeza» puede resultar, por otra parte, una manera simbólica de referirse a un ritual de recolección de hongos visionarios en el que el «sombrerillo» es arrancado de su pie, como también la perdieron Orfeo, cuya cabeza siguió profetizando después de arrancada, igual que la perdió Penteo, que se op0uso al culto de Dionisoso, y cuya cabeza fue arrancada por su propia madre Agave ${ }^{17}$.

\section{UN POCO DE MITOLOGÍA CLÁSICA}

También en el Jardín de las Hespérides, según los mitos griegos, un dragón, como encarnación del centinela o guardián arquetípico, guardaba el mágico árbol de frutos dorados, al igual que un otro dragón guardaba el Vellocino de Oro. Las Hespérides, que significan «las Vespertinas» O «Las Occidentales», eran hijas de la Noche o de Héspero, según las versiones, y tenían a su cargo el cuidado del famoso jardín. Según otros testimonios las Hespérides, unos seres que destacan por su voz, al igual que las sirenas y que cambiaban de forma enloqueciendo a quienes las veían, custodiaban un jardín maravilloso lleno de fuentes de ambrosía, consagrado a Hera, porque la diosa había plantado allí las manzanas doradas que recibió de Gea como regalo de bodas. Se trata, que duda cabe, del jardín paradisiaco y los alimentos (se decía que las propias manzanas podían tornar inmortal al que las comiera) que confieren la inmortalidad, un lugar, junto al que se encontraban también las Gorgonas, al tiempo celeste y subterráneo, un punto de conjunción de los extremos del universo ${ }^{18}$.

15 SHAFEER, A., «Gilgamesh, the Cedar Forest and Mesopotamian History», Journal of the American Oriental Society, 103, 1 (1983) p. 309.

${ }_{16}$ GEORGE, A. R., The Epic of Gilgamesh (http://eprints.soas.ac.uk/8611/1/CUPGilg.pdf), p. 8.

17 GRAVES, R., «EL Paraíso Universal», Desde el Jardín de Freud, 7, (2007), p. 263.

18 AGUIRRE CASTRO, M., "Ambigüedad y otros caracteres en las divinidades remotas de la épica arcaica», Cuadernos de Filología Clásica, 6 (1996) pp. 153 ss. 
En un vaso griego procedente del sur de Italia y fechado en el tercer cuarto del siglo IV a. C., Perseo corta con una hoz la cabeza de la gorgona Medusa, que descansa junto a un árbol, en una escena presidida por hongos ${ }^{19}$. Llama poderosamente la atención, además de la presencia de los hongos, el que el héroe utilice para su cometido no un arma, sino lo que se considera un instrumento de herbolario. Por cierto que Perseo, en el mito, adquiere la capacidad chamámica de volar y el don de la invisibilidad gracias a la sustracción de las sandalias aladas y del yelmo de Hades que poseían las Fórcides, sobrinas de las Gorgonas, para arrancar la cabeza de Medusa, que hechizaba a quién la mirara, como leemos en Apolodoro20 y Ovidio'1.

En realidad, el mito de Perseo parece describir el ritual mágico de recolección de un hongo visionario ${ }^{22}$. De la cabeza cercenada de Medusa surgieron dos criaturas fabulosas, Pegaso y Crisaor. Pegaso era un caballo alado que al nacer ascendió al Olimpo, donde se puso al servicio de Zeus, llevándole el rayo. Gracias a su ayuda Belerofonte, que parece un doble o un alter ego de Perseo, pudo matar al monstruo Quimera y vencer a las Amazonas. Crisaor, que al nacer blandía una espada de oro, desposó a Calirroe, una oceánide, y de ambos nacieron dos monstruos, Gerión el enemigo triforme de Heracles, y Equidna, con cuerpo de mujer terminado en una cola de serpiente. Se dice que esta última vivía en un caverna en Cilicia, en el país de los arimos y que había engendrado, a su vez, numerosos monstruos, entre ellos Cerbero, el guardián del Hades, la Hidra de Lerna, la propia Quimera y el dragón de Cólquide que guardaba el Vellocino de Oro. Resulta curioso constatar que el mismo Heracles, en el curso de uno de sus célebres trabajos, dio muerte a la Hidra de Lerna, un reptil de numerosas cabezas cuyo hálito era mortal, no con una espada, una lanza o un hacha, como cabría esperar, sino con una harpe, esto es, una hoz o guadaña, como la que había utilizado Perseo ${ }^{23}$. ¿Había tenido la hidra originariamente una naturaleza botánica?

Por otra parte, algunos mitos griegos hablan de una droga que proporcionaba la inmortalidad. Tal ocurre, por ejemplo, con Calypso, ninfa de extraordinaria belleza que reside en una isla en el lejano Océano occidental, y que era capaz de otorgarla, lo que solo puede ser obtenido de otro modo por medio de la ambrosía. Cuando Hermes fue a visitarla por encargo de Zeus la encontró en la gran caverna en la que había hecho su residencia ante un fuego y a lo largo de la isla flotaba el olor de las hogueras de cedro y enebro24. Sus similitudes con la mesopotámica Siduri-Sabitu fueron señaladas hace tiempo por M. S. Jensen ${ }^{25}$. Thetis rodeaba de

19 TRENDALL, A. D., The Red -Figured Vases of Lucania, Campania and Sicily, Oxford, 1967, cap. $\mathrm{XVI} \cap \circ 335$

20 Biblio, II, 4

21 Met., IV, 774 ss.

22 RUCK, C. A. P., «Las ofrendas de los Hiperbóreos» en: La búsqueda de Perséfone. Los enteógenos y el origen de la religión, México, 1996, p. 331.

23 Apolodoro, Biblio, II, 4.

24 Odisea, V, 5 ss.

25 ALBRIGHT, W.F., «The Goddess of Life and Wisdom», The American Journal of Semitic Languages and Literatures, 36, 4 (1920), pp 261 ss. 
noche al niño Aquiles con fuego y de día ungía sus tiernas carnes con ambrosía para hacerlo inmortal y salvarlo de los horrores de la vejez ${ }^{26}$, lo que recuerda muy de cerca el proceder de Demeter con el hijo de Deyanira, reina de Eleusis. En el mito de Tántalo éste fue castigado por querer proporcionar a la humanidad la ambrosía, el alimento de los dioses, con lo que llegaría a ser como ellos, según la tradición, que recogen, entre otros, Píndaro ${ }^{27}$ y Apolodoro ${ }^{28}$. Las fuentes más antiguas aún mantienen la tradición de ambrosía como bebida, así que, originalmente, parece que néctar, la bebida de los dioses, y ambrosía eran similares. También en la religión védica figuraba junto a Soma, Amrita, literalmente «sin muerte» en sánscrito, la bebida que proporcionaba la inmortalidad a las divinidades ${ }^{29}$.

Pero ¿se trataba de la misma droga con la que Gea había pretendido convertir en inmortales a los Gigantes?, lo que fue finalmente frustrado por Zeus. Según el mito, tal y como nos recuerda Apolodoro ${ }^{30}$ :

\begin{abstract}
«Gea, irritada a causa de los Titanes, procrea con Urano a los Gigantes: insuperables por su tamaño e invencibles por su fuerza, mostraban temible aspecto, con espesa pelambre pendiente de la cabeza y el mentón, y escamas de dragón como pies (...) Arrojaban al cielo encinas encendidas y piedras. Aventajaban a todos Porfirio y Alcioneo -que era inmortal mientras combatiera en su tierra nativa(...). A los dioses se les había vaticinado que no podrían aniquilar a ningún gigante a menos que un mortal combatiera a su lado. Conociendo esto Gea busca una droga para que no poudieran ser vencidos ni por un mortal. Pero Zeus prohibió aparecer a Eos, Selene y Helios,, y adelantándose, él mismo destruyó la sustancia y por medio de Atenea llamó a Heracles en su ayuda».
\end{abstract}

(Trad. M. Rodríguez de Sepúlveda).

Dicho de otra forma, el triunfo de Zeus y los demás dioses sobre los gigantes podría estar representando el encumbramiento de las divinidades olímpicas sobre las ancestrales fuerzas ctónicas de la religión primitiva, la sustitución por la liturgia de los cultos ciudadanos de las antiguas manifestaciones extáticas propias de los rituales preolímpicos, la purga del antiguo enteógeno, que quedará recluido en los Misterios, y su sustitución por el vino dionisiáco ${ }^{31}$. Tal vez el mito de Tifón, monstruo creado por Gea tras la derrota de los Gigantes, y de cuyos muslos surgían enormes anillos de víboras, nos esté indicando la resistencia de la vieja religión a desaparecer. Zeus combatió contra él armado también con una hoz ${ }^{32}$, lo que una vez más sugiere su naturaleza botánica.

26 Apolonio de Rodas, Argon, IV, 757 ss.

27 Ep., 2, 1

28 Biblio, epit, 2, 1.

${ }^{29}$ CROWLEY, M., «When gods drank urine. A Tibetan myth may help solve the riddle of soma, sacred drug of ancient India»: http://www.takeourword.com/urine.html.

30 Biblio., I, 6, 1.

31 WAGNER, C. G., «Artemis, Quirón y Dionisos. Una aproximación etnobotánica», en: C. Fornis, J Gallego, P. López Barja y M. Valdés (eds.) Dialéctica Histórica y compromiso social. Hmenaje a Domingo Plácido, vol. 3, Madrid, 2010, p. 1251.

32 Apolodoro, Biblio., I, 6, 3. 
Volviendo al Poema de Gilgamesh, en una plegaria hitita Humbaba es representado como un pájaro, lo que no cuadra mucho con su caracterización como gigante. Pero sabemos que los pájaros eran vistos por las gentes de muchas culturas preurbanas como manifestaciones chamánicas. Y Humbaba, según el mito, pertenece a los tiempos anteriores a la civilización. Por otra parte, de acuerdo con J. Derakhshani ${ }^{33}$ el nombre de Humbaba procedería de -hauma-pâna-, el protector de la planta del Haoma, el equivalente iranio al Soma védico, aunque el debate sobre el origen de su nombre es considerable ${ }^{34}$.

En definitiva, el monstruoso protector de un bosque de árboles sagrados de mágicas propiedades muere tras perder la cabeza como Tifón, otro gigante, o la Medusa. ¿Oculta, en realidad, la existencia originaria de un hongo enteógeno u otro tipo de planta psicoactiva que crecía en el bosque, como manaba la ambrosía en el Jardín de las Hespérides? Al fín y al cabo, Gilgamesh fue en su busca para realizar una proeza sobrehumana que lo equiparara a un dios. Pero claro, esto ya no responde, de verificarse la hipótesis, a un patrón común indoeuropeo, o sí, de aceptar la identificación de su nombre que propone Derakhshani, si bien los dioses del Próximo Oriente también bebían un "Vino de la vida Eterna», que les era proporcionado por Siduri-Sabitu, diosa-serpiente de la Vida y la Sabiduría, aquella que recibió a Gilgamesh en el Jardín de los Dioses.

\section{LLEGADA AL PARAÍSO}

El Poema de Gilgamesh recoge varias de las tradiciones más antiguas, que durante generaciones debieron de ser transmitidas por vía oral antes de su fijación canónica por escrito. Una de ellas es la búsqueda de Utanapishtim «el lejano», el único hombre al que los dioses la han concedido el don de la inmortalidad y que habita en los confines del mundo. Nuestro héroe comienza su búsqueda tras la muerte de su compañero y amigo Enkidu, abatido y obsesionado con la idea de su propia muerte. Para ello cruzará el vasto desierto infestado de leones hasta alcanzar el monte Mashu, coronado por dos elevadas cumbres gemelas, donde un oscuro y largo desfiladero es el itinerario que el Sol recorre cada día para alumbrar el mundo. Su acceso estaba guardado por los terribles hombres-escorpión, que finalmente le indican el camino. Tras atravesar la oscuridad, Gilgamesh llega al mágico Jardín de los Dioses donde árboles, frutos y flores eran como piedras preciosas (y una vez más la evocación del Jardín de las Hespérides con sus frutos dorados se vuelve imperiosa). Esta claro que cualquier intento de comprender la naturaleza física de tal Jardín está condenado al fracaso. De echo, el lugar, que en las versiones más antiguas del Poema representa uno de los límites del mundo, como el otro lo representa el Bosque de los Cedros, ya que la incorporación del

33 «Die Arier in den nahöstlichen Quellen des 3. und 2. Jahrtausends V. Chr.», Iran and the Caucasus, 2, 1 (1983) pp. 24-37.

${ }^{34}$ HANSMAN, J., «Gilgamesh..., p. 26. 
episodio de Utanapishtin y el Diluvio parece un añadido posterior ${ }^{35}$, es el resultado de una experiencia visionaria.

Desgraciadamente en esta parte, el documento original -la tablilla de arcillaestá roto por lo que se ha perdido la mayor parte de su descripción. Resultará curioso saber que esta experiencia de Gilgamesh ha sido catalogada por los expertos en la materia como una «experiencia de muerte cercana ${ }^{36}$ » y que las investigaciones sobre este tipo de experiencias las vinculan también con el chamanismo y los estados de trance chamánicos ${ }^{37}$. Puesto que las "experiencias de muerte cercana» y aquellas otras en las que el sujeto se percibe saliendo de su propio cuerpo han sido también experimentadas por personas invidentes, algunos investigadores han sugerido que tal vez se trate de un tipo de estado alterado de la consciencia capaz de provocar una visión sin la necesidad sensorial de los ojos ${ }^{38}$, mientras que también se ha señalado, por otra parte, que la administración de sustancias alucinógenas, como la ketamina, pueden llegar a producir un tipo de experiencias muy similares ${ }^{39}$. En cualquier caso, las experiencias de «muerte cercana» parecen compartir con otras experiencias trascendentales, como los estados de trance chamánicos entre otras, un cierto comportamiento neurofisiológico del cerebro $^{40}$. Incluso se ha sugerido que la glándula pineal pueda producir en determinadas circunstancias una sustancia similar a la dimetil-tryptamina y que sea la responsable de producir tales experiencias ${ }^{41}$.

De acuerdo con Lara Peinado42: «El poeta se atrevió a describir, si bien parco en palabras, una alucinante escenografía recorrida por Gilgamesh en busca de la inmortalidad, cuyo secreto conocía, sin embargo, uno de sus antepasados. El héroe, hambriento, soportando fríos y calores, vestido con harapos de pieles, cazando fieras, evitando peligros, viajará hacia el oeste en búsqueda de su antepasado, Utanapishtim, atravesando una geografía fantástica a la que todo lo humano le es ajeno. Su odisea terrestre lo lleva hasta el Océano, junto a las Aguas de la Muerte, detrás de las cuales espera hallar la luz que ahuyente de modo definitivo las tinieblas, y sobre todo su angustia, que siente clavada en su estómago. «Una mitología de pesadilla reemplaza a toda la realidad conocida.»

35 DICKSON, K., «The Jeweled Trees: Alterity in Gilgamesh», Comparative Literature, 59, 3 (2007) p. 195

${ }^{36}$ SCHROTER-KUNHARDT, M., "A review of near death experiences», Journal of Scientific Exploration, Vol. 7, 3 (1993) p. 225.

37 TIMOTHY GREEN, J., «Near-Death Experiencies, Shamanism and the Scientific Method», Journal of Near-Death Studies, 16, 3 (1998) pp. 205-222; Id, «The Near-Death Exprience as a Shamanic Initiation: A Case Study», Journal of Near-Death Studies, 19, 4 (2001) pp. 209- 225.

38 RING, K. - COOPER, S., "Near-Death and Out-of-Body Experiences in the Blind: A Study of Apparent Eyeless Vision», Journal of Near-Death Studies, 16, 2 (1997) pp. 101-147.

39 JANSEN, K. L. R, «The Ketamine Model of the Near-Death Experience: A Central Role for the NMethyl-D-Aspartate Recpetor», Journal of Near Death Studies, 16, 1 (1997) p. 26.

40 JOURDAN, J. P., «Near-Death Experiences and Trasncendental Experiences. Neurophysiological correlates and hypotheses», Journal of Near Death Studies, 12, 3 (1994), pp. 177-200.

${ }^{41}$ HILL, D.R. - PERSINGER, M. A., «Aplication of Transcerebral weak (1 micro T) complex magnetic fileds and Mystical Experiences: are they generated by fiel-induced dimethyltryptamine release from the pineal organ?», Perceptual and Motor Skills, 97 (2003) pp. 1049-1050.

42 «Poema de Gilgamesh..., p. 12. 
Tras la oscuridad, un paraíso de vívidos colores. ¿No nos recuerda nada? Precisamente esta es una de las visiones más frecuentes narradas por aquellos que han experimentado seriamente con los enteógenos. Por otra parte, está la interesante teoría de que las muy similares visiones del Paraíso en muchas de las religiones del planeta, un huerto o espléndido jardín, con un estanque o un río bordeados de flores y árboles enjoyados, proceden, en realidad, de la visión inducida químicamente por una planta mágica o sagrada. De hecho hay toda una multitud de testimonios contemporáneos que lo corroboran. Por ejemplo, el de R. Graves ${ }^{43}$ nada sospechoso de veleidades neochamánicas. Y la iconografía conservada de diversas tradiciones culturales aporta el resto. Allí el alma permanece arrobada, extasiada de felicidad y de asombro, como el propio Gilgamesh en el Jardín de los Dioses ${ }^{44}$ :

«Y Gilgamesh iba y venía entre estas maravillas... Alzó los ojos...»

Por supuesto, tales visiones pueden ser obtenidas por los místicos sin el empleo de un droga psicoactiva, pero no parece que nuestro protagonista sea precisamente un asceta. Por otro lado, a fin de no descartar ninguna posibilidad, las privaciones a que se ve sometido en su largo viaje por el desierto y tras cruzar las entrañas de la montaña, han podido desatar en él un estado alterado de conciencia que explique su visión del Paraíso. Además, conviene recordar ahora, que algunos investigadores sostienen que la oscuridad y el empleo de drogas visionarias en determinadas celebraciones rituales podrían ser una explicación a las imágenes entópticas del arte prehistórico ${ }^{45}$. ¿Estaba Gilgamesh en una situación similar? ¿Ingirió tras sus largas penalidades algún fruto capaz de inducirle la visión?

Sospecho que el Jardín encantado de las Piedras Preciosas, el Jardín de los Dioses situado bajo la tutela de Siduri-Sabitu, divinidad dispensadora del Vino de la Vida Eterna, podía contener varios especímenes semejantes. Al parecer se trata de una antigua divinidad marítima sumeria, que según otra tradición mesopotámica era la protectora del Arbol de la Vida, lo cual sugiere ciertas connotaciones botánicas y farmacológicas bien conocidas. "If Siduri was in one story the goal of the hero's quest of life, she must have been regarded as the goddess or nymph in whose hands lay its disposal, or, to employ the universally known symbolism, as the keeper of the fruit of life and the fountain of life. In the incantatory series, Surpu, II, 172 , she is called 'goddess of wisdom, genius of life' (il Siduri liptur il Istar nimeqi il lamassi baldti), and in a late Assyrian letter (Harper, V, 476, 20) her name occurs between Anunît, a name of Istar as queen of heaven (consort of Anu), and Mummu, god of wisdom. 259 ss.

${ }^{43}$ GRAVES, R., Los dos nacimientos de Dionisio, Barcelona, 1984, pp. 99 ss. Id, «EL Paraíso..., pp.

44 IX, 35.

45 LEWIS-WILLIAM, J. D., «Wrestling with Analogy: A Methodological Dilemma in Upper Paleolitic Art Research», Proceedings of the Prehistoric Society, 57, 1 (1991) pp. 149-162; DRONFIELD, J., «Migraine, Ligth and Hallucinogens: The Neurocogtinive basis of Irish Megalithic Art», Oxford Journal of Archaeology, 14, 3 (1995) pp. 261-275. 
El Poema de Gilgamesh: algunas preguntas desde la etnobotánica...

... Her intimate association and virtual interchange with serpent deities, her character as goddess of life and wisdom as vine deity and as genius of life, like Esir, all point in that direction. As a virgin nymph she is naturally to be classified with the snake nymphs (ginns) and Naga princesses of the Orient. ${ }^{46}$

\section{EL BARQUERO Y LAS AGUAS DE LA MUERTE}

En un principio, Siduri-Sabitu desaconseja a Gilgamesh su búsqueda de la inmortalidad 47 :

«Gilgamesh, ¿por qué vagas de un lado para otro?

La Vida que persigues no la encontrarás jamás.

Cuando los dioses crearon la Humanidad,

asignaron la muerte para esa Humanidad,

pero ellos retuvieron entre sus manos la Vida.

En cuanto a ti, Gilgamesh, Ilena tu vientre,

vive alegre día y noche,

que tus vestidos sean inmaculados,

lávate la cabeza, báñate,

atiende al niño que te tome de la mano,

deleita a tu mujer, abrazada contra ti.

¡Tal es el destino de la Humanidad!»

La pregunta es inevitable. ¿Cómo retuvieron los dioses entre sus manos la Vida que le está vedada a Gilgamesh? ¿Escondieron tal vez al conocimiento de los mortales creados por ellos la existencia del Pan de la Vida y el Agua de la Vida? En cualquier caso, ante la insistencia de Gilgamesh, Siduri-Sabitu le indica el camino, no recorrido por ningún mortal, para llegar hasta Utanapishtim «el lejano». Debe encontrar primero al barquero Urshanabi, que según ella, se encuentra en el bosque 48 :

«cortando ramas de cedro de pequeño tamaño»

para que le ayude a atravesar las «Aguas de la Muerte», el Océano impenetrable que redea el mundo habitado, y poder alcanzar su objetivo.

Uno de los traductores y editores del poema ${ }^{49}$ se pregunta sobre el sentido de esta recogida de ramas. La clave está, sin embargo, en la naturaleza de tal tipo de cedro. Puesto que el viaje de Gilgamesh parece haberle conducido hacia los confines del mundo a las orillas del Océano podemos desacartar los cedros del Lí-

46 ALBRIGTH, W. F., «The Goddess..., pp. 260 y 274.

47 Frag. Meisnner (Col. III, 1-14).

$48 \mathrm{X}, 29$

49 BOTTERO, J., La epopeya..., p. 201, n. 22. 
bano.. En efecto, este tipo de cedro, cuyo aceite esencial ${ }^{50}$ puede resultar neurotóxico en dosis elevadas, se daba sobre todo en los bosques de montaña de Líbano, Turquía y Siria, siendo su ambiente óptimo entre los los 1300 y 1800 metros de altitud $^{51}$.

Pero Gilgamesh se encuentra a orillas del mar, por lo que los cedros cuyas pequeñas ramas recoge el barquero han de ser de otro tipo. En este sentido, es necesario recordar, como ya hemos hecho, que la denominación de «cedro» se aplicaba a una cierta variedad de árboles. Uno de ellos es el denominado en los textos cuneiformes erin-bad, cedro blanco o Juniperus oxycedrus, también conocido como junípero, enebro albar o enebro de la nieve. Se trata de una especie de muy amplia difusión por toda la región mediterránea y a menudo se encuentra en bajas altitudes próximas al nivel del mar. Por el contrario, empieza a escasear a los 1000 metros de altura.

Su uso estaba muy desarrollado en la farmacopea mesopotámica, como ya hemos visto ${ }^{52}$ y formaba parte de los inciensos que inspiraban los oráculos de los sacerdotes baru en Babilonia y de los inciensos utilizados por los cananeos y otros pueblos del Próximo Oriente Antiguo ${ }^{53}$. Es muy probable que el barquero, que debía acompañar a Gilgamesh en su peligroso viaje por las Aguas de la Muerte, entendidas como un vasto e impenetrable Océano, se encontrara recogiendo pequeñas ramas de cedro blanco a fin de preparar con ellas una fumigación psicoactiva. Ello se deduce de todo el contexto de la narración, llena de elementos visionarios, como el Jardín de los Dioses o la conversación con la diosa protectora del Arbol de la Vida, y de sus propios acompañantes, unos seres misteriosos similares a estatuas de piedra animadas que debían acompañarles en el viaje y a los que finalmente Gilgamesh destroza.

\section{UTANAPISHTIN Y EL DILUVIO: INCIENSO Y VISIÓN DE LOS DIOSES}

Por cierto que tras recorrer las Aguas de la Muerte, que nos recuerdan el «paso acuático» del viaje iniciático del chamán al inframundo, Gilgamesh escucha de Utanapishtin el relato sobre su inmortalidad. Al haberse salvado del Diluvio gracias al oportuno aviso del dios Ea, se le concedió finalmente, junto con su mujer, ser como dioses, pero vivir alejados, en los confines del mundo. En este punto, es preciso señalar que Utanapishtin es un héroe primordial en un mito relacionado con la Creación de la Humanidad, y que en muchas culturas tales mitos contienen cla-

50 BASER, K. H. C. -. DEMIRÇAKMAK, B., «The essential oil of taurus cedar (Cedrus libani a. rich): recent results», Chemistry of Natural Compounds, 31, 1 (1995) pp. 16-20.

51 LAWS, G., «The Cedar of Lebanon», Garden History, 4, 1 (1976), pp. 54-56; CHANEY, W. R.- BASBUS, M., «The cedars of Lebanon witnesses of history», Economic Botany, 32, 2 (1978), pp. 118-123.

52 Vid, n. 9.

53 GODBEY, A. E., «Incense..., pp. 236 ss; cfr. GOETZE, A., «An old prayer of the divination priest»,JCS, 22 (1968-9), p. 26. 
El Poema de Gilgamesh: algunas preguntas desde la etnobotánica...

ras alusiones a una planta mágica capaz de proporcionar el conocimiento y la inmortalidad. Tal planta no es otra que el Arbol de la Vida.

Por otra parte, Utanapishtin parece haber estado al corriente de los conocimientos botánicos y farmacológicos capaces de provocar la aparición de los dioses. En su relato a Gilgamesh explica, que una vez terminado el Diluvio y después que el cuervo que había soltado ya no volvió, señal inequívoca de que había encontrado tierra ${ }^{54}$ :

«Entonces, lo dispersé todo a los cuatro vientos.

e hice un banquete para los dioses,

poniendo los manjares

en la cima de la montaña.

Coloqué a cada lado

siete vasos rituales,

y más atrás en el quema-perfumes

cimbo(pogon), cedro y mirto».

(Trad. J. Botteró)

Como vemos, el cedro forma parte del incienso y también la planta que el traductor del texto da como «cimbopogon», al parecer denominación erudita de una planta que podría ser cálamo o caña aromática (Acorus calamus), cuya raíz contiene asarona, un éter fenólico cristalino, que se encuentra en aceites esenciales de plantas como la artemisa vulgar y que a dosis elevadas produce alucinaciones ${ }^{55}$, y b-asarona, susceptible de convertirse en trimetilanfentamina, una sustancia con una potencia psicoactiva diez veces superior a la mescalina ${ }^{56}$. Tras esto, no es raro que Utanapishtim tuviera una visión del propio dios Enlil subiendo a su barco para concederle la inmortalidad. Según J. Botteró ${ }^{57}$ estos versos parecen proceder de algún ritual o inspirarse en él. De ser cierto, estaríamos ante uno de los testimonios de la existencia de antiguos rituales mesopotámicos en los que se empleaban plantas de efectos psicoactivos.

Curiosamente, la utilización de inciensos capaces de provocar visiones en el transcurso de algunos rituales había sido ya observado por alguno de los grandes orientalistas de la segunda mitad del siglo XIX, aunque luego el tema no volviera a ser muy tratado. Citando a J. P. Brown, autor del famoso The Dervishes or Oriental Spiritualism, publicado en Londres en 1868, Godbey ${ }^{58}$ dice: «Brown reminds us that the incense used in the worship of the paphian Venus and Syrian Astarte soothed the votary upon his temple couch and files him with visions of granted desires». Inciensos psicoactivos destinados a provocar visiones fueron utilizados en el

\footnotetext{
$54 \mathrm{XI}, 155$ ss.

55 OTT, J., Pharmakotheon. Drogas enteógenas, sus fuentes vegetales, Barcelona, 2000, p. 359.

56 MILLER, R.A., El uso mágico y ritual de las hierbas, Santa Fe, 1995, p. 60.

57 La epopeya..., p. 228, n. 278.

58 «Incense..., p. 220.
} 
culto de Shamash, Astarté, Adón, Artemis o Tanit, entre otras divinidades ${ }^{59}$. Según estudios recientes realizados por investigadores de la John Hopkins University y de la Universidad de Jerusalem, la resina de Boswellia, uno de los ingredientes comunes del más famoso y difundido de todos los inciensos conocidos (frankincense), es psicoactiva y causa una serie de efectos sobre el cerebro como son aliviar la ansiedad y la depresión, facilitando la exaltación espiritual ${ }^{60}$.

En este sentido, las palabras de K. Nielsen ${ }^{61}$ resultan muy ilustrativas: «The fragance of incense works like a drug which ensures the favorable disposition of the gods towards man. It make them give positive oracles, it makes them forgive sins. The fragance of incense purifies the mind of the gods as well as the mind of the man. It is the perfect medium for establishing communication between the divine and human sphere». Pero ¿qué ocurriría si en ocasiones, como parece, algunos inciensos contenían sustancias psicoactivas y visionarias?

\section{LA PLANTA DE LA ETERNA JUVENTUD}

Tras su relato, Utanapishtim somete a Gilgamesh a una prueba que consiste en permanecer despierto seis días y siete noches noches, justo lo que había durado el Diluvio, lo que sugiere ciertas connotaciones iniciáticas. La falta prolongada de sueño puede llegar a alterar el funcionamiento fisioquímico del cerebro produciendo estados alterados de conciencia y cierto tipo de visiones. No obstante, nuestro héroe fracasa al quedarse dormido al poco tiempo. En realidad cae en un sueño profundo que dura siete días. Tras este fracaso, Gilgamesh se dispone a iniciar el camino de regreso, cuando Utanapishtim le hace partícipe de un secreto de los dioses ${ }^{62}$ :
«Se trata de una planta
con la raíz semejante a la del falso jazmín
y cuyas espinas
son como las de la zarza,
listas para pincharte las manos.
Si consigues hacerte con ella
habrás encontrado la vida prolongada»

(Trad. J. Botteró)

Todo este episodio de Gilgamesh y la búsqueda de la Planta Mágica parece una historia independiente del resto del Poema. En realidad puede tratarse de una

\footnotetext{
59 WAGNER, C. G.., «Sobre inciensos, trances y (algunas) diosas», 'llu. Revista de Ciencias de las Religiones, 15 (2010), pp. 91-103.

60 MOUSSAIEFF, A., et al., «Incensole acetate, an incense component, elicits psychoactivity by activating TrpV3 channels in the brain», The FASEB Journal, 22 (2008,) pp. 3024-3034.

61 Incense in Ancient Israel, Leiden, 1986, p. 30.

$62 \mathrm{XI}, 268 \mathrm{ss}$.
} 
historia original sobre la explicación de la extensa longevidad de las poblaciones antediluvianas $^{63}$. Si es así, su longevidad se explica por el acceso a un planta mágica (la planta era conocida como shibu issakhir amelu, «El anciano se rejuvenece») antes de que los dioses la ocultaran en el Abzu tras las aguas del Diluvio. En los exorcismos mesopotámicos a menudo aparecen mencionadas «las plantas de las montañas y las plantas del abismo" como dos categorías de plantas mágicas, relacionadas ambas con los dioses, unas por medio de la Montaña, morada de las divinidades, las otras por medio del Abzu. Si esto es así ya no hay que pensar en una planta exclusivamente acuática, sino que cualquier otra especie antediluviana pudo ser ocultad por los dioses en el Abzu, igual que los dioses griegos ocultaron néctar y ambrosía, que les hacía inmortales, a los humanos.

En cualquier caso no hay acuerdo sobre la identificación botánica de esta planta, capaz de rejuvenecer pero no de conceder la inmortalidad. No se trata, por tanto de un enteógeno, pero debía poseer virtudes vigorizantes. Se ha pensado que podía ser alguna especie de lycium, plantas de la familia de las solanáceas de las que solo en Eurasia se dan unas diez especies, bien conocidas por la herbalística y la medicina antiguas. Para encontrar esta planta, que no hay que confundir con el Arbol de la Vida del Jardín de los Dioses, Gilgamesh ha de descender al abismal fondo del Abzu, el Mar Primordial situado debajo del mundo, según las concepciones cosmológicas mesopotámicas. Un viaje de tipo chamánico en busca de una planta mágica que puede devolver la juventud y prolongar la vida.

No obstante, tras haberla conseguido, mientras estaba tomando un descanso y dándose un baño en una poza de agua fresca, una serpiente, atraída por el olor de la planta, se la arrebató y a continuación mudó la piel, lo que en la Antigüedad se tenía por símbolo de rejuvenecimiento. Así que Gilgamesh ha de volver a Uruk sin ella. En la Antigüedad las serpientes están muy a menudo relacionadas con las toxinas y venenos, sobre todo vegetales, ya que se consideraba que podían tomar su veneno de las plantas, así como trasmitirlo a ellas ${ }^{64}$. El hecho de que mudaran la piel era, por otra parte, interpretado como un símbolo de muerte y resurrección espiritual. Por ello se las asociaba también con frecuencia con la inmortalidad, y, por supuesto con el Arbol de la Vida. Pero también se las relacionaba con los hongos y se pensaba que éstos podían adquirir la toxina de la serpiente si esta se encontraba cerca. Como señala Plinio65:

«No es difícil ver el razonamiento que está detrás de la vieja relación entre la serpiente y el hongo que ha tenido un papel tan grande en las creencias populares sobre los hongos y en los mitos. Ambos surgen de agujeros en el suelo de forma semejante al miembro viril que despierta al impulso sexual, y ambos llevan en sus cabezas un fuerte veneno que los antiguos creían que podían trasmitirse entre sí».

63 VEENKER, R. A., «Gilgamesh and the Magic Plant», Biblical Archaeologist (1981), pp. 199-205.

64 Nicandro, Alexipharmaca, 521-525.

65 Nat. Hist., XXII, 95. 
Según la leyenda sumeria de Arata, que fue elevado al cielo por un águila en busca de una planta milagrosa que provocaba los nacimientos (lo que vuelve a recordarnos el viaje ascendente del chamán), el ave engañó a la serpiente, con la que previamente había llegado a un acuerdo, devorando luego a sus crías. Ahora bien, en el Rig Veda encontramos una clara relación entre el águila y Soma (la bebida intoxicante que preside todo el ritual védico) ${ }^{66}$. Ya que, al margen de los debates sobre su identificación botánica, existe común acuerdo sobre las propiedades psicoactivas de la planta soma de la que se extraía la pócima ritual, otra pregunta surge casi inevitablemente: ¿representaba simbólicamente la serpiente de la leyenda de Arata alguna planta de estas características? ¿Necesitaba ingerirla el águila para alcanzar el éxito en su vuelo de ascenso hacia el cielo de los dioses?

De toda esta parte del poema, llaman la atención una cosa. Habiendo visto el Paraíso, Gilgamesh no fue capaz de identificar el Arbol de la Vida, y su protectora, la diosa Siduri-Sabitu, no le proporciona ninguna indicación al respecto. Tampoco lo hace Utanapishtim, que no menciona siquiera de que manera los dioses le convirtieron en inmortal, aunque en otro mito mesopotámico, el de Adapa, el protagonista, tras haber ascendido al Cielo, rehusa la inmortalidad, engañado por el dios Ea, al no querer comer «el Pan de la Vida» ni beber «el Agua de la Vida» ${ }^{67}$. Al parecer, este alimento de la vida y el agua de la vida tenían propiedades mágicas y no era necesario ingerirlos para que surtieran efecto, pero estaban, en principio, reservados a los dioses. Tal es la forma en la que Innana logra salir del Mundo Inferior: debe ser rociada con alimento de la vida y bebida de la vida ${ }^{68}$, y así volverá a vivir. ¿Era el primitivo enteógeno mesopotámico algún tipo de solanácea piscoactiva? El cualquier caso, todo parece indicar que la elite religiosa había preservado para si, en el momento de la redacción del poema, sino antes, el conocimiento y el uso de los enteógenos, modificando la tradición oral originaria.

${ }^{66}$ KNIPE, D. M., «The Heroic Theft: Myths from Rgveda IV and the Ancient Near East», History of Religions, 6, 4 (1967), pp. 328 ss.

67 ANET, 101-103

68 BOTTERO, J. - KRAMER, S. N., Cuando los dioses hacían de hombres. Mitología mesopotámica, Madrid, 2004, p. 301. 